\title{
Cauliflower (Brassica oleraceavar. botrytis L.) Production Applied with Carabao Manure: Effects on Growth and Yield
}

\author{
Leah C. Tuan, Ph.D
}

*Associate Professor, Department of Agricultural Sciences, College of Agriculture, Fisheries, and Natural Resources, University of Eastern Philippines, University Town, Northern Samar, Philippines

Email: leahtuanc@gmail.com

\begin{abstract}
Utilization of carabao manure as a sustainable approach on nutrient management for cauliflower production was studied for three months between the months of October 2016 to January 2017 at the University Demo Farm, University of Eastern Philippines, Main Campus, University Town, Catarman, Northern Samar, Philippines. The main objective was to determine the effect of carabao manure on the growth and yield of cauliflower. Carabao manure preparations included dried carabao manure, administered at $1.0 \mathrm{~kg}$ and $1.5 \mathrm{~kg}$ levels boosted with manure tea.

Growth and yield performance of cauliflowers were significantly influenced by dried carabao manure applications boosted with manure tea application. Better performance were observed in plants treated with 1.5 $\mathrm{kg}$ dried carabao manure than with $1.0 \mathrm{~kg}$ was evident on the parameters evaluated, indicative of the nutrient sufficiency of the bio fertilizer.

Carabao manure, a farm waste product, an untapped resource, has been proven to be an effective, safe and an economical bio organic fertilizer. A commodity capable of becoming a promising industry; a lowly resource, but if given enough attention can "turn dust into gold" and effect significant changes in the lives of many sort. Keywords-Animal wastes, Bio-organic fertilizer, Carabao manure tea, Dried carabao manure.
\end{abstract}

\section{INTRODUCTION}

Nutrient management and insect pest control are indispensable in any farming endeavour. Undoubtedly, the use of most appropriate technology suited to a given croplargely contribute to its growth and yield.

The utilization of indigenous farm resources such as farm manure and botanicals relative to crop management as an organic production technology has a good number of assured chain of benefits which are: environmental sanitation or ecological conservation, reduction of production cost resulting to bigger income, and production of genuinely safe food crops to address and promote health and wellness concerns.

Carabaomanure, is a very good bio material for enhancing soil fertility. This bio-organic resource can be collected in every farm. Rosco, 2014, (personal communication), mentioned that a carabao produces ten (10) kilos of manure a day. Chemical analysis shows that carabao manure has 18-20 C:N ratio. It has $24-30 \%$ carbon, 0.8-2.2 \% Nitrogen, 2.07 Phosphorus, and 0.122.0 Potassium (Aganon, et al., 2011). They further cited that manure from ruminants is found to enhance plant growth because of the decomposing microorganisms in the rumen and hormones in their urine.

With these, the study was conceived to test the efficacy of carabao manure as fertilizer as bio fertilizer on the growth and yield of cauliflower grown pots.

\section{METHODOLOGY}

Experimental Design and Treatments. A randomized complete block design (RCBD) with three replications was used. Three doses of bio-organic fertilizer from animal wastes were evaluated, to wit: No carabao manure (DCMO -control); $1.0 \mathrm{~kg}$ dried carabao manure (DCM1) and $1.5 \mathrm{~kg}$ dried carabao manure (DCM1.5). The treatments were designated as follows:

T1: DCMO - No Carabao Manure (DCMO-Control)

T2: DCM1 $\quad-\quad 1.0 \mathrm{~kg}$ Carabao

Manure

T3: $\quad$ DCM1.5 - $1.5 \mathrm{~kg}$ Carabao manure

Preparation and Application of Carabao Manure as Bio-organic Fertilizer. Carabao manure was processed in two ways: dried (DCM) and manure tea (CMT). Dried carabao manure was collected and air- 
dried until it was totally dried, while carabao manure tea was processed by submerging a sack-full of partially dried carabao manure in a 200-liter capacity plastic drum filled with ground water for one week before its use.

Dried carabao manure (DCM) was prepared in two levels: 33 and $50 \mathrm{t} / \mathrm{ha}$ converted into $1.0 \mathrm{~kg}$ (DCM1) and $1.5 \mathrm{~kg}$ (DCM1.5), respectively. Application of DCM was done once for DCM1 and twice for DCM1.5. Application of DCM1 was adminstered as basal before planting; while second application for DCM1.5 as top dress was done 10 days after the first application. Carabao manure tea $(\mathrm{CMT})$ at the rate of $100 \mathrm{ml}$ plant was applied in each plant at planting and at weekly interval thereafter throughout the duration of the study. Application was directed in the soil at the base of each plant.

Planting and Harvesting. Hardened cauliflower seedlings (Farmers' Extra Early variety) were transplanted to the plastic pots filled with desired volume of soil medium and bio-organic fertilizer late in the afternoon to reduce transplanting shock. The plants were maintained using recommended cultural management practices. Gowth and yield was measured in terms of plant height, length and width of leaves, leaf area and weight at harvest, weight of whole plant, root-shoot-ratio, number of days to $50 \%$ flowering, weight and diameter of curd and yield of marketable curds. Harvesting was done when the curd became compact and firm or about 50 days from transplanting. Data gathered were analyzed employing the analysis of variance (ANOVA) and treatment mean differences were determiend using the Least Significance Difference (LSD) test at 5\% level of probability.

\section{RESULTS AND DISCUSSION}

\section{Growth Characters}

Growth characters as influenced by the application of carabao manure as bio-organic fertilizer are summarized in Table 1.

Plant Height at Harvest (cm).Plants applied with $1.0 \mathrm{~kg}$ dried carabao manure (DCM1) were tallest, $39.83 \mathrm{~cm}$ followed by plants applied with $1.5 \mathrm{~kg}$ dried carabao manure or (DCM1.5) with $38.35 \mathrm{~cm}$. Plants were shortest in pots without dried carabao manure (DCM0) at $35.05 \mathrm{~cm}$.Although carabao manure is considered a slow release organic fertilizer, its effect might have been enhanced by the application of carabao manure tea (CMT), boosting plant nutrients at early crop stage resulting to the rapid growth of the cauliflowers.Jigmei, N.J., et al., (2015) reported an increase in growth parameters of broccoli applied with chicken and manure tea; and El-Magd, et al., (2016), noted accelerated growth of the plants applied with organic manure.

Number of Leaves per Plant at Harvest.Although the number of leaves produced per plant varied according to carabao manure application, the same was not significant. The production of almost the same number of leaves with or without the application of different levels of DCM indicates that the cauliflower variety used in the study can adapt to local conditions even in soils with low fertility level. This observation is true in almost all vegetable (Brassica) researches in the area where the control (without fertilizer application) plants were able to develop considerable number of leaves but of different length, breadth and weight subject to available nutrients in the soil (Tuan, 2002).

Leaf Length at Harvest (cm).Length of cauliflower leaves was significantly affected by the application of carabao manure. Longest leaves were found in DCM1 $(19.55 \mathrm{~cm})$ and DCM1.5 $(21.02 \mathrm{~cm})$; shortest leaves were noted in DCM0 $(15.32 \mathrm{~cm})$. Higher rates of carabao manure produced bigger and longer leaves. This implies that DCM added with CMT provided adequate nutrients to the cauliflowers. This corroborates the findings of Fayed (2010) who claimed that CMT significantly increased the vegetative parameters of the Roghini olive trees. In addition, Eltantawy (2009) also found out that farmyard compost tea increased the height and leaf area of potato plant.

LeafWidth at Harvest (cm).Plants applied with DCM1 and DCM1.5 produced the widest leaves while those applied with DCMO only had the narrowest leaves.The production of wider leaves in cauliflowers is necessary to support flower/curd formation. Results of this study revealed that formation of bigger and wider leaves is directly related to the application of DCM with CMT as sources of nutrient. Gross et al.(2008), reported that ammonium is the major form of nitrogen present in the extract solutions from all manure types and that the nitrogen released after 14-day extraction by the different methods from the different manures ranged between $50 \%$ and 85\%. Alo and Tuan (2015) obtained almost similar result in cauliflower applied with chicken dung.

Leaf Area at Harvest (cm). The application of DCM significantly influenced the leaf area of cauliflower plants. Highest leaf area was recorded among plants applied with DCM1 with $654.26 \mathrm{~cm}^{2}$ and those with DCM1.5 with $632.84 \mathrm{~cm}^{2}$. Lowest leaf area was observed in the control plants (DCM0) with $403.71 \mathrm{~cm}^{2}$. No significant difference in leaf area was observed between DCM1 and DCM1.5. The variation in leaf area observed among treatments being bigger in plants applied with 
DCM than those in control plants (DCM), implies that DCM has sufficient nutrients. Nourishment received by the plants enabled the production of bigger and wider leaves; a plant requirement that allow optimum light interception and distribution for efficient physiologic process such as photosynthesis and carbohydrate transport (El-Sawy et al., 200; el-Dis soky, 2008) which contribute to the formation of reproductive parts in cauliflower.

Leaf Weight at Harvest (g).Different rates of DCM had significant influence on the weight of cauliflower leaves per plant. Average leaf weight per plant was heaviest in DCM1 at $381.39 \mathrm{~g}$, and DCM1.5 with $375.55 \mathrm{~g}$, but no significant difference was observed between them.Lightest leaves were observed in plants not applied with DCMO (213.09 g). The variation in leaf weight among treatments is directly related to the size of the leaves (leaf length, width, area) produced by the plants. Based on the other growth parameters, it can be noted that the longest and widest leaves and biggest leaf area were produced by the plants treated with DCM. Gross et al., 2008, mentioned that organic fertilizers have the property to enhance soil aggregation, soilaeration, and water holding capacity; factors which offer good environmental condition to broccoli plants.

Weight of Whole Plant at harvest. Weightof whole plants differed significantly as influenced by the application of DCM. Average weight of whole plants applied with DCM1 was $235.83 \mathrm{~g}$ and DCM1.5 with $221.20 \mathrm{~g}$ were statistically the same except on plants without DCM with $139.12 \mathrm{~g}$. Weight of whole plant comprises all plant parts including the roots. The results of the study relative to the weight of the whole plant almost follow similar pattern with the other growth parameters evaluated such as the vegetative parts (leaf length, width and leaf area). The increase in vegetative growth can be traced back to the positive effects of DCM with CMT which have contributed to the increase in photosynthetic activity and uptake of soil nutrient. These results are in agreement with the findings of Caser (2009) in cauliflower, Elkhatib, (2009) on common bean.

Shoot-Root Ratio.Shoot-rootratio was highest in plants treated with DCM1.5, $8.33 \mathrm{~g}$ followed by plants treated with DCM1.0 with $8.85 \mathrm{~g}$ and those without DCM at $6.77 \mathrm{~g}$ per plant. Although highest shoot- ratio was highest in plants applied with DCM1.5 followed by plants applied with DCM1 and those without carabao manure (DCMO), in the descending order, the differences were not significant. The higher shoot-root ratio among treatment treated with organic fertilizer is indicative that the plants were receiving sufficient nutrients to support a large vegetative (shoot) growth. Wright et al. (1995), observed that maximum root growth and rooting depth of barley crop were higher in treatments, which received animal manures relative to where manure was not applied. The results therefore suggest that the observed response was largely due to increased availability of $\mathrm{N}$ and $\mathrm{P}$ in Carabao manure and manure tea and consequently enhanced root growth.

\section{Yield Parameters}

Yield parameters as influenced by the application of carabao manure as bio-organic fertilizer are presented in Table 2.

Number of Days from Transplanting to 50\% Flowering. The number of days from transplanting to $50 \%$ flower/curd formation as influenced by the application of the different rates of DCM wassignificant. Flowering/curd formation was earliest, 42.29 days in plants applied with DCM1.5 but delayed for about three days, 45.25 in plants applied with DCM1, and up to five days, 48.54 inuntreated plants. Notably, the cauliflower variety (Farmers' Extra Early) used in this study is an early maturing variety, produces curds which can be harvested within 40 days from transplanting. Based on the results, generally, plants which were organically fertilized flowered earlier compared to those which were not fertilized; possibly due to better nourishment. The lack of nutrients for immediate utilization in control plants may have contributed to the delay in flower/curd formation.

Curd Diameter (cm) at Harvest. Curd diameter considerably differed among the treatments evaluated. Cauliflowers applied with DCM1.5 produced the biggest curd, $11.68 \mathrm{~cm}$, those applied with DCM1 produced smaller curd, $10.06 \mathrm{~cm}$. Plants which did not receive DCM produced undersized curds $(7.64 \mathrm{~cm}$. The production of bigger curd in the fertilized treatmentscan be attributed to the cumulative contributions of healthy vegetative plants parts produced in plants receiving organic fertilizer as results of readily available nutrients and better mobilization of plant nutrients translocated by the application of bio-fertilizer.

Curd Weight at harvest. Results of the study relative to the application of different rates of DCM revealed positive impact on weight of cauliflower curd. Consistently, those applied with dried carabao manure (DCM1 and DCM1.5) showed the heaviest curds, while those without carabao manure (DCMO) had the lightest. In harmony with other growth and yield parameters evaluated in this study, treatments administered with DCM and CMTalso registered heavier curds. Better growth and yield performance are manifestations of nutrient sufficiency provided to the plants by the bio organic resources. 
Table 1. Growth characters of cauliflower as influenced by the application of carabao manure.

Mean*

\begin{tabular}{c|cccccccc}
\hline Treatments & $\begin{array}{c}\text { Plant } \\
\text { Height } \\
(\mathrm{cm})\end{array}$ & $\begin{array}{c}\text { Number } \\
\text { of leaves } \\
\text { per plant }\end{array}$ & $\begin{array}{c}\text { Leaf } \\
\text { length at } \\
\text { harvest } \\
(\mathrm{cm})\end{array}$ & $\begin{array}{c}\text { Leaf } \\
\text { width at } \\
\text { harvest } \\
(\mathrm{cm})\end{array}$ & $\begin{array}{c}\text { Leaf area } \\
\text { at harvest } \\
\left(\mathrm{cm}^{2}\right)\end{array}$ & $\begin{array}{c}\text { Leaf } \\
\text { weight at } \\
\text { harvest }\end{array}$ & $\begin{array}{c}\text { Weight } \\
\text { of whole } \\
\text { Plant }(\mathrm{g})\end{array}$ & $\begin{array}{c}\text { Root- } \\
\text { shoot } \\
\text { Ratio }\end{array}$ \\
M0 & $35.05^{\mathrm{b}}$ & 16.18 & $15.32^{\mathrm{b}}$ & $9.18^{\mathrm{b}}$ & $134.57^{\mathrm{b}}$ & $71.03^{\mathrm{b}}$ & $19.87^{\mathrm{b}}$ & 6.77 \\
$M 1$ & $39.83^{\mathrm{a}}$ & 17.06 & $19.55^{\mathrm{b}}$ & $11.38^{\mathrm{a}}$ & $218.09^{\mathrm{a}}$ & $125.18^{\mathrm{a}}$ & $27.24^{\mathrm{a}}$ & 7.42 \\
$M 2$ & $38.35^{\mathrm{a}}$ & 17.06 & $21.02^{\mathrm{a}}$ & $11.83^{\mathrm{a}}$ & $210.95^{\mathrm{a}}$ & $127.13^{\mathrm{a}}$ & $25.58^{\mathrm{a}}$ & 8.33
\end{tabular}

*Means followed by the same letter are not significant at 5\% DMRT.

\section{Average Yield of Marketable Curd Yield}

$(t / h a)$. Yield of marketable curd greatly varied as affected by the application of dried carabao manure but failed to register significant differences between treatments. Higher yield in plants applied with carabao manure and carabao manure tea is the concrete manifestation of the overall plant performance given favourable environment (physically conducive and nutritionally sufficient). Expectedly, plants reared in such condition had produced big and heavy curds. Based on the production indices evaluated in this study, the application of carabao manure as an organic bio fertilizer supplemented with manure tea almost resulted to sizable vegetative growth.

Table 2. Yield characters of cauliflower as influenced by the application of carabao manure.

Mean*

\begin{tabular}{|c|c|c|c|c|}
\hline Treatments & $\begin{array}{l}\text { Number of Days to } \\
50 \% \text { Flowering }\end{array}$ & $\begin{array}{l}\text { Curd diameter } \\
\text { at harvest } \\
(\mathrm{cm})\end{array}$ & $\begin{array}{l}\text { Weight of marketable } \\
\text { curd at harvest } \\
(\mathrm{g})\end{array}$ & $\begin{array}{l}\text { Yield of marketable } \\
\text { curd } \\
\text { (t/ha) }\end{array}$ \\
\hline MO & $48.54^{\mathrm{a}}$ & $7.64^{c}$ & $74.56^{\mathrm{b}}$ & 2.44 \\
\hline$M 1$ & $45.25^{\mathrm{b}}$ & $10.06^{\mathrm{b}}$ & $184.26^{\mathrm{a}}$ & 3.05 \\
\hline$M 2$ & $42.29^{c}$ & $11.68^{\mathrm{a}}$ & $208.29^{a}$ & 3.59 \\
\hline
\end{tabular}

* Means followed by the same letter are not significant at 5\% DMRT.

\section{CONCLUSION AND RECOMMENDATIONS}

The application of carabao manure complemented with carabao manure tea as source of bio-organic fertilizer for cauliflower production was found to have highly influenced the growth and yield of cauliflowers, evident on the different growth and yield parameters evaluated, such as plant height, length and width of leaves, leaf area and weight at harvest, weight of whole plant, root-shoot-ratio, number of days to $50 \%$ flowering, weight and diameter of curd and yield of marketable curds. Carabao manure with manure tea was found to be effective in influencing growth and yield of cauliflower. Higher rates of carabao manure enhanced with manure tea resulted to bigger and heavier plants and eventually higher yield of marketable cauliflowers

Carabao manure and carabao manure tea, a farm waste, is rich in plant nutrients and beneficial microorganisms is a potential bio-organic fertilizer productive and sustainable organic cauliflower production. A follow-up study is necessary to further verify the performance of cauliflower applied with carabao manure with manure tea under farmers field conditions.

\section{ACKNOWLEDGEMENT}

The researcher wish to express her profound thanks to the University of Eastern Philippines (UEP) administration and the Commission on Higher Education (CHED) for the material and financial support that leads in the realization of this experiment. To the University Research and Development Services staff, and field workers who assisted the researchers throughout the duration of the experimentation.

\section{REFERENCES}

[1] Abou El- Magd, M.M., A.M, El-Bassiony and Z.F. Fawzy . 2016. Effectof Organic Manure with or Without Chemical 
Fertilizerson Growth,Yield and Quality of Some Varieties of Broccoli Plants

[2] Alo, L.D. and Tuan, P.P. 2014. Growth and Yield of Cauliflower(Brassica oleracea) Applied with Chicken Dungbased Organic Fertilizer under Polyethylene Pot Culture. UEPGS MS Thesis.

[3] Caser G. Abdel.2009. Improving the Production of Well Irrigated Cauliflower (Brassica oleraceavar.Botrytis, $\mathrm{Cv}$. Snowball Y. Imp) by Foliar Spraying of some Growth Regulators. Journal of Zankoy Sulaimani12(1), 29-49.

[4] DOST. (1998): Madre de cacao. Department of Science and Trade. Manila, Philippines.Stoll, G. (2000): Natural protection in the tropics. MargrafVer Weikersheim.www.bar.gov.ph

[5] El-Dissoky, R. A. 2008. Studies on the use efficiency of potassium and organic fertilizers on potatoes and its role in improving soil properties.PhD Thesis. Faculty of Agriculture, Mansoura, University,Egy pt.

[6] Elkhatib HA. 2009. Growth and yield of commonbean(Phaseolus vulgaris L.) in response to Rhizobium Inoculation, nitrogen and molybdenium fertilization. Alex. Sci.Exchange Journal 30, 319- 332.

[7] El-Sawy, B. I., Radawan, E. A. and Hassan, N. A. 2000. Growth and yield of potato as affected by soil and foliar potassium application. Journal of Agriculture Science, 25(9):5843-5850.

[8] El-Tantawy, I. M., El-Ghamry, A. M. and Habib, A. H. 2009. Impact of farmy ard manure and manure compost tea on potato yield and soil fertility. Journal of Agriculture Science, 34(1): $669-678$.

[9] Fayed, T. A. 2010. Optimizing yield, fruit quality and nutrient status of Roghiani olive grown in Libya using some organic extracts. Journal of Horticulture Science and Ornamental Plants, 2(2): 63-78.

[10] Gross, A., Arusi, R. and Nejidat, A. 2007. Assessment of extraction methods with fowl manure for the production of liquid organic fertilizers. Bioresource Technology, 99: 327334.

[11] Jigme1, Nipon Jay amangkala1, PathipanSutigoolabud, JiraponInthasan and Siriwat Sakhonwasee1.2015. The effect of Organic fertilizers on growth and yield of Broccoli (Brassica oleraceaL. var. italicaPlenck cv. Top Green) Journal of Organic Systems, 10(1),

[12] PCARRD. 1999. Broccoli and Cauliflower Production Guide. Information Bulletin No. 148. Los Banos 4030 Laguna.

[13] Rodriguez AA. January 2012. "Sariaya, Quezon Organic Farmer Succeeds with Cauliflower". Agriculture Monthly. Volume 16, Issue 01. p. 44.

[14] Samonte P. August 2012 . "Bataan Farmer earns Millions FromCalamansi and Vegetables". Agriculture Monthly. Volume 16, Issue 8. pp.20-21
[15] Samonte P. March 2013. "Organic Farming Develops Roots In Pampanga”. Agriculture Monthly. Vol 17, Issue No. 3 pp $52-53$. 